\title{
Reduced risk of low weight births among indigent women receiving care from nurse-midwives
}

\author{
Paul F Visintainer, Jane Uman, Kathy Horgan, Angela Ibald, Uma Verma, Nergesh Tejani
}

\begin{abstract}
Study objective-To examine the effect of a comprehensive prenatal and delivery programme administered by nursemidwives on the risk of low weight births among indigent women.

Study design-Historical prospective study. Birth outcomes among the cohort were compared with all county births during the same period, adjusting for maternal age and race. Results are expressed as relative risks with $95 \%$ confidence intervals.

Setting-An enhanced Medicaid funded pre-natal programme administered by nurse-midwives from 1992 to 1994 in Westchester County, New York.

Participants-Indigent mothers $(n=1443)$, between the ages of 15 and 44, who were residents of Westchester County and indicated having Medicaid or no health care coverage.

Results-There were 1474 live births among cohort mothers. Mean (SD) gestational age was $39.4(1.9)$ weeks. Less than $6 \%$ of births occurred before 37 weeks gestation. The mean birth weight of cohort infants was 3365.6 (518.6) g. Only $4.1 \%$ of the cohort births were less than 2500 g. Compared with all county births, the cohort showed a $41 \%$ reduction in the risk of low weight births $\left(\mathbf{R R}_{\mathrm{lbw}}=\mathbf{0 . 5 9}\right.$, 95\%CI: 0.46 to $0.73, \mathrm{p}<.001$ ) and a $56 \%$ reduction when compared with county Medicaid births only $(R R=0.44,95 \% C I$ : 0.34 to $0.57, p<.005$ ) adjusting for maternal age and race. Larger reductions were found for very low weight births.

Conclusions-Mothers need not be considered at high risk for adverse pregnancy outcomes based on their socioeconomic status alone. Moreover, a comprehensive prenatal programme administered by nurse-midwifes may promote a reduction in adverse pregnancy outcomes among indigent mothers.

(F Epidemiol Community Health 2000;54:233-238)
\end{abstract}

Women of low socioeconomic (SES) status traditionally have been considered at high risk for adverse pregnancy outcomes. Previous studies have shown that several SES indicators, such as maternal education, ${ }^{12}$ paternal occupation, ${ }^{3}$ income level, ${ }^{2}{ }^{4}$ and census tract ${ }^{56}$ influence preterm birth and low birth weight. The increased risk associated with these crude indicators of SES is probably mediated through high risk behaviours and adverse environments that are globally related with SES. ${ }^{78}$
For example, behaviours such as smoking and alcohol consumption, ${ }^{9}$ and delayed onset of prenatal care, ${ }^{10}$ as well as measures of poverty such as poor housing and level of violence, ${ }^{6}$ in the past have been associated with rates of low birth weight.

Attempts to modify behavioural risk factors through comprehensive prenatal care have had mixed results. On the one hand, observational studies generally suggest that enhanced prenatal care may improve birth weight outcomes. However, except for smoking cessation, which has been shown to increase birth weight, ${ }^{11} 12$ clinical trials testing various aspects of prenatal care have yielded conflicting results. ${ }^{113-18}$ While most trials show negligible overall effects of intervention, some identify subgroups that seem to benefit from the intervention. ${ }^{13} 1517$ Yet, as intractable as the problem may be to intervention, the human and economic cost of low birth weight dictates that efforts to reduce the rate of low birth weight continue.

We had a unique opportunity to examine the birth outcomes in a cohort of low income women (hereafter referred to as "indigent") attending a nurse-midwife programme. By the end of the last decade, a local publication had drawn attention to the increasing rate of adverse pregnancy outcomes in Westchester County, NY. ${ }^{19}$ The increase was largely attributed to adverse outcomes among indigent mothers. The trend seemed to parallel several notable demographic changes occurring in the county over the same period: a rapid rise in the indigent and immigrant population, increasing rates of unemployment, increases in births to teenage mothers, and single parent families.

In response to these trends, a collaboration among the New York Medical College's Department of Obstetrics and Gynecology, the Westchester Medical Center, and St Agnes Hospital initiated a nurse-midwife programme to provide quality obstetrical and gynaecological services to indigent women of Westchester County. The programme was designed to meet the more rigorous standards of the state's Prenatal Care Assistance Program (PCAP). Under PCAP, additional financial incentives are provided to institutions that expand basic prenatal care. To qualify for PCAP reimbursement, participating institutions must provide improved case management and referral services, improved continuity of care, counselling, and a range of behavioural risk reduction programmes. Comprehensive care includes health education and nutrition services, prenatal diagnostic and treatment services, as well as after hour access and emergency consults. ${ }^{20}$ 
The programme is reviewed annually by the state to insure adherence to standards.

The institution began offering services in August of 1991 in three ambulatory, community-based locations in lower Westchester County. A major goal of the initiative was to provide a comprehensive programme of services at each location, substantially improving availability of care. At each site patients had access to counselling, and individual and group instruction on childbirth, nutrition, and exercise. Also, a Medicaid worker was present to initiate and expedite enrolment and processing of federal assistance programmes.

Nurse-midwives administered prenatal care, conducted training, and attended to births. They also served as an initial triage for mothers presenting with conditions or behaviours considered high risk for adverse birth outcomes. Mothers presenting with evidence of drug abuse, diabetes (non-diet controlled), gestational hypertension, or other conditions requiring specialised care at the tertiary care centre were transferred to the Division of Maternal and Fetal Medicine at the Westchester Medical Center. Additionally, women requesting elective procedures, such as tubal ligation, were also sent to the medical centre.

This study reports on data collected during the three year period from 1992 to 1994 .

\section{Methods}

COHORT

The study cohort comprised women who delivered through the nurse-midwife programme during the three year period from 1992 to 1994 . A mother was considered part of the cohort if she was a resident of Westchester County between the ages of 15 and 44 , and indicated having either Medicaid or no health care coverage. As the nurse-midwife programme was created to target indigent mothers specifically, no indigent women were excluded from participating. It was estimated that about $90 \%$ of mothers who begin the programme eventually deliver through the programme.* Births included in the cohort were live births greater than or equal to 23 weeks gestation. A total of 1443 women and 1474 live births met criteria during the three year period.

Nurse-midwives delivered the majority of births in the cohort. However, 102 (6.9\%) births were transferred to WMC because of high risk conditions or elective procedures. It should be pointed out that all indigent mothers who contacted the nurse-midwife programme were included in the cohort, irrespective of where the majority of care was received or where delivery occurred. As such, mother and infant transfers were included in the cohort.

$\star$ Because of restricted access to old medical records and limited resources, we are unable to obtain the participation rate of the 1992-1994 cohort. However, previous reports on the nursemidwives programme indicate that about $90 \%$ of mothers who midwives programme indicate that about $90 \%$ of mothers who begin the programme eventually deliver through the programme. To confirm this estimate, we examined a sample of 100 indigent mothers enroled in the nurse-midwife programme during 1998. In this sample, $89 \%$ delivered through the programme (including those triaged to Westchester Medical Center), $8 \%$ had an early pregnancy loss, and $3 \%$ were lost to follow up.
For comparison, the live birth experience of Westchester County for the same period was obtained from the New York State Department of Health. Rates were computed for low birth weight $(<2500 \mathrm{~g})$ and very low birth weight $(<1500 \mathrm{~g})$ stratified by five year age groups $(15$ to 44 ) and by race (black compared with other) for the entire county and for Medicaid births. Births from the state database that were missing data on these factors were dropped from the regression analyses.

DETERMINING RACE AND ETHNICITY

Information on race and ethnicity was collected to adjust the outcome rates for comparisons with the county. Race and ethnicity was obtained from two different sources: the patient's chart and the admissions log. Race from the admission log was obtained for all mothers $(n=1474)$, whereas race determined from the patient's chart was missing for 62 . After reviewing the classification schemes used for collecting race and ethnicity data in the cohort, we decided to code race as AfricanAmerican compared with other using the data from the admission $\log$. This decision was made because we were unable to distinguish Hispanic ethnicity from African-American or white race using the two sources of data. Of the 1412 women who had data on race and ethnicity from the two sources, the category of African-American was coded most consistently between the patient record and admissions log than any other classification. Chance adjusted agreement, $(\kappa)$, for coding African-American compared with other was 0.88 (95\% CI: 0.85 to $0.91)$, indicating excellent agreement. ${ }^{21}$ The $\kappa$ for coding white compared with other was 0.57 (95\%CI: 0.54 to 0.60 ). Chance adjusted agreement for Hispanic compared with other was 0.28 ( $95 \% \mathrm{CI}: 0.23$ to 0.33 ).

Configuring the race variable as either African-American or other is likely to provide adequate adjustment for two reasons. AfricanAmerican women, as a group, have rates of preterm birth and low birth weight that are higher than both white and Hispanic women and Hispanic women have rates that are similar to white women. ${ }^{22} 23$

\section{OUTCOMES}

The outcomes of interest were low birth weight defined as a live birth weighing less than 2500 g. Additionally, we were interested in very low birth weight defined as a live birth weighing less than $1500 \mathrm{~g}$. Other characteristics of delivery and care, such as mode of delivery and time at which prenatal care was initiated, were obtained from patient records and nursing logs.

The spontaneous fetal death rate at 20 or greater weeks gestation was computed according to the definition used by the state health department. This rate is the number of fetal deaths $(\geqslant 20$ weeks $)$ divided by the total number of live births plus the number of spontaneous fetal deaths ( $\geqslant 20$ weeks). Presentation is restricted to descriptive statistics as the number of events was small. 
Table 1 Characteristics of cohort infants at delivery

\begin{tabular}{|c|c|}
\hline Characteristics & Distribution \\
\hline Gestational age (weeks) mean (SD) & $39.4(1.9)$ \\
\hline \multicolumn{2}{|l|}{ Gestational age (n, \%) } \\
\hline$\geqslant 37$ weeks & $1395(94.6)$ \\
\hline $33-36$ weeks & $68(4.6)$ \\
\hline$\leqslant 32$ & $11(0.8)$ \\
\hline Birth weight (g) mean (SD) & $3365.6(518.6)$ \\
\hline \multicolumn{2}{|l|}{ Low birth weight $(n, \%)$} \\
\hline$<1500 \mathrm{~g}$ & $9(0.6)$ \\
\hline $1500 \mathrm{~g}-2499 \mathrm{~g}$ & $52(3.5)$ \\
\hline$\geqslant 2500 \mathrm{~g}$ & $1413(95.9)$ \\
\hline \multicolumn{2}{|l|}{ Gender (n, \%) } \\
\hline Male & $764(51.8)$ \\
\hline Female & $710(48.2)$ \\
\hline \multicolumn{2}{|l|}{ APGAR at 5 minutes $(n, \%)$} \\
\hline$<7$ & $15(1.0)$ \\
\hline$\geqslant 7$ & $1458(99.0)$ \\
\hline
\end{tabular}

STATISTICAL METHODS

Data were analysed using Poisson regression to compare the birth weight outcomes in the cohort with those of the county. Firstly, data were collapsed over the three year period to increase the number of outcomes in age and race strata. Separate regression models were constructed for low birth weight and very low birth weight. For each of these birth weight outcomes, three distinct models were generated using different county distributions for comparison: all county births (including Medicaid births), all non-Medicaid county births, and county Medicaid births only. Each of the final six models controlled for five year age group and race. The six age groups were modelled with five indicator variables using the youngest age group (15-19) as the reference category. Race was modelled as a dichotomous variable (black $v$ other), using "other" as the reference. For the comparison of the cohort with county, the county was coded as the reference category.

The relative risk estimates from the Poisson regression models were compared with those obtained from indirect standardisation and the results were found to be nearly identical. Only results from the regression models are presented for the major analyses. When indirect standardisation is used, results are expressed as a standardised morbidity ratio (SMR). Values less than 1.0 occur when there are fewer

Table 2 Description of selected maternal and birth characteristics for the midwife cohort and the county

\begin{tabular}{lll}
\hline Characteristic & $\begin{array}{l}\text { Midwife cohort } \\
(n=1474) \text { Number }(\%)\end{array}$ & $\begin{array}{l}\text { Total county experience* } \\
(n=39749) \text { Number }(\%)\end{array}$ \\
\hline $\begin{array}{l}\text { Low birth weight } \\
<2500 \mathrm{~g}\end{array}$ & $61(4.1)$ & $2743(6.9)$ \\
$<1500 \mathrm{~g}$ & $9(0.6)$ & $556(1.4)$ \\
Caesarean section (n=1473) & $330(22.4)$ & $10187(26.6)$ \\
Initiated prenatal care & $(\mathrm{n}=1423)$ & $(\mathrm{n}=35881)$ \\
First & $527(37.0)$ & $27515(76.7)$ \\
Second & $683(48.0)$ & $6436(17.9)$ \\
Third & $213(15.0)$ & $1930(5.4)$ \\
Parity & & $(\mathrm{n}=39528)$ \\
First & $735(49.9)$ & $17609(43.8)$ \\
Second & $438(29.7)$ & $13263(34.0)$ \\
Third & $196(13.3)$ & $5752(14.8)$ \\
Fourth & $105(7.1)$ & $2904(7.5)$ \\
Maternal age & & $(\mathrm{n}=38988)$ \\
15-19 & $195(13.3)$ & $2047(5.3)$ \\
$20-25$ & $476(32.4)$ & $5005(12.8)$ \\
$25-29$ & $397(26.9)$ & $10586(27.2)$ \\
$30-34$ & $277(18.8)$ & $13549(34.8)$ \\
$35-39$ & $109(7.4)$ & $6687(17.2)$ \\
$40-44$ & $20(1.4)$ & $1114(2.9)$ \\
\hline
\end{tabular}

*Total live births in county. observed events than expected events. Values greater than 1.0 occur when the converse is true.

Results are presented as relative risks with $95 \%$ confidence intervals. For other comparisons, the $\chi^{2}$ test was used, as most variables were categorical in nature.

\section{Results}

The cohort consisted of 1474 live births among 1443 mothers. Maternal characteristics are described for each birth $(n=1474)$. The average age was 25.9 (5.8) years and $15.9 \%$ $(n=234)$ had identified themselves as AfricanAmerican. Approximately $92 \%$ of mothers were on Medicaid $(n=1360)$ at the time of delivery, whereas the remainder had no medical coverage. The total number of births includes 102 births $(6.9 \%)$ that were transferred to the Westchester Medical Center because of high risk or elective procedures.

Table 1 presents the characteristics of cohort infants at delivery. The mean gestational age was 39.4 weeks, with less than $6 \%$ of births occurring before 37 weeks gestation. The mean birth weight of cohort infants was $3365.6 \mathrm{~g}$. Only $4.1 \%$ of the cohort births were less than 2500 g. A total of 15 births (1.0\%) had APGAR scores less than 7.0.

Table 2 shows unadjusted comparisons between the birth cohort and the total birth experience of Westchester County for characteristics of interest. The cohort had lower rates of low weight births and very low weight births, as well as a lower rate of caesarean sections compared with the county. With regard to initiation of prenatal care, more than $75 \%$ of all pregnancies in the county initiated prenatal care in the first trimester. In the cohort, only $37 \%$ of mothers initiated prenatal care in the first trimester.

Table 3 shows the relative risks of low birth weight for the cohort. Adjusting for maternal age and race, the nurse-midwife cohort exhibited lower risk of low weight births relative to each of the three county comparison groups. Compared with the total county experience, the cohort showed a significant $41 \%$ reduction in the risk of low birth weight $\left(\mathrm{RR}_{\mathrm{bbw}}=0.59\right.$, $95 \%$ CI: 0.46 to $0.73, \mathrm{p}<.001)$. The degree of risk reduction was attenuated somewhat when the cohort was compared with all nonMedicaid births in the county. In this comparison, the cohort experienced a significant 35\% reduction in the risk of low weight births $\left(\mathrm{RR}_{\mathrm{bbw}}=0.65,95 \% \mathrm{CI}: 0.50\right.$ to $\left.0.85, \mathrm{p}=.002\right)$. The largest risk reductions were seen when the cohort was compared with county Medicaid births only. Cohort mothers had a $56 \%$ reduction in the risk of low weight births $\left(\mathrm{RR}_{\mathrm{lbw}}=0.44,95 \% \mathrm{CI}: 0.34\right.$ to $\left.0.57, \mathrm{p}<.001\right)$.

A similar pattern of results was found for very low weight births as shown in table 4 . The cohort realised a $56 \%$ reduction in risk compared with all county births $\left(\mathrm{RR}_{\mathrm{vlbw}}=0.44\right.$, 95\% CI: 0.23 to $0.85, \mathrm{p}<.015)$ and a $54 \%$ reduction in all non-Medicaid births $\left(R_{\mathrm{v}}\right.$ $\mathrm{lbw}^{\mathrm{b}}=0.46,95 \% \mathrm{CI}: 0.23$ to $\left.0.89, \mathrm{p}<.02\right)$. Compared with county Medicaid births only, cohort 
Table 3 Relative risk of low birth weight $(<2500 \mathrm{~g}$ ) among cohort mothers, adjusting for age group and race

\begin{tabular}{llll}
\hline Variables in model & $\begin{array}{l}\text { All county births } \\
(\text { model 1) }\end{array}$ & $\begin{array}{l}\text { All non-Medicaid } \\
\text { county births (model 2) }\end{array}$ & $\begin{array}{l}\text { County Medicaid births } \\
\text { only (model 3) }\end{array}$ \\
\hline $\begin{array}{l}\text { Cohort } v \text { county } \\
\text { Black } v \text { other }\end{array}$ & $0.59(0.46,0.73)$ & $0.65(0.50,0.85)$ & $0.44(0.34,0.57)$ \\
Age group & $2.03(1.86,2.21)$ & $2.03(1.80,2.29)$ & $1.59(1.40,1.79)$ \\
$\quad 15-19^{\star}$ & 1.0 & & \\
$20-24$ & $0.83(0.70,0.98)$ & $0.71(0.49,1.01)$ & $0.89(0.74,1.08)$ \\
$25-29$ & $0.82(0.70,0.96)$ & $0.76(0.54,1.06)$ & $0.98(0.81,1.19)$ \\
$30-34$ & $0.82(0.70,0.96)$ & $0.75(0.53,1.05)$ & $1.14(0.93,1.40)$ \\
$35-39$ & $0.82(0.69,0.97)$ & $0.76(0.53,1.07)$ & $1.12(0.86,1.44)$ \\
$40-44$ & $1.24(0.97,1.58)$ & $1.13(0.76,1.70)$ & $1.61(1.06,2.45)$ \\
\hline
\end{tabular}

${ }^{\star}$ Indicates reference group.

Table 4 Relative risk of very low birth weight $(<1500 \mathrm{~g})$ among cohort mothers, adjusting for age group and race

\begin{tabular}{llll}
\hline Variables in model & $\begin{array}{l}\text { All county births } \\
\text { (model 1) }\end{array}$ & $\begin{array}{l}\text { All non-Medicaid } \\
\text { county birth (model 2) }\end{array}$ & $\begin{array}{l}\text { County Medicaid births } \\
\text { only (model 3) }\end{array}$ \\
\hline $\begin{array}{l}\text { Cohort } v \text { county } \\
\text { Black } v \text { other }\end{array}$ & $0.44(0.23,0.85)$ & $0.46(0.23,0.89)$ & $0.32(0.16,0.63)$ \\
Age group & $2.56(2.14,3.06)$ & $2.94(2.31,3.74)$ & $1.66(1.26,2.18)$ \\
$\quad 15-19^{\star}$ & 1.0 & & \\
$20-24$ & $1.06(0.72,1.56)$ & $1.03(0.45,2.35)$ & $1.04(0.67,1.63)$ \\
$25-29$ & $1.03(0.71,1.49)$ & $0.95(0.43,2.08)$ & $1.10(0.70,1.75)$ \\
$30-34$ & $1.03(0.72,1.49)$ & $0.89(0.41,1.94)$ & $1.52(0.96,2.41)$ \\
$35-39$ & $1.04(0.70,1.56)$ & $0.90(0.40,2.00)$ & $1.56(0.89,2.74)$ \\
$40-44$ & $1.73(1.00,2.97)$ & $1.69(0.69,4.14)$ & $1.51(0.53,4.31)$ \\
\hline
\end{tabular}

${ }^{\star}$ Indicates reference group.

mothers had a $68 \%$ reduction in the risk of very low weight births $\left(\mathrm{RR}_{\mathrm{vlbw}}=0.32,95 \% \mathrm{CI}: 0.16\right.$ to $0.63, \mathrm{p}=.001$ ).

There were 10 fetal deaths at 20 weeks gestation or later, yielding a three year cumulative incidence of 6.7 deaths per 1000. The spontaneous fetal death rate for the county was 6.3 per 1000 for the same period. Adjusting for race, the expected number of fetal deaths in the cohort was 9.5. The corresponding SMR was 1.05 ( $95 \%$ CI: 0.51 to $1.94, \mathrm{p}=0.48$ ).

\section{Discussion}

This study compared the birth experience of indigent mothers participating in a nursemidwife programme with the birth experience of the county overall and the county's Medicaid population. After adjusting for maternal age and race, the nurse-midwife cohort experienced reductions in the risk of low birth weight of $35 \%$ to $55 \%$, when compared with the overall county rate and the county Medicaid rate, respectively. For very low weight births, reductions within cohort were in the order of $55 \%$ to $65 \%$. The reductions in risk are particularly striking in light of the later initiation of prenatal care for cohort participants compared with the county.

The results of this study are consistent with several earlier studies comparing mothers receiving enhanced or coordinated prenatal care with those receiving regular care. Buescher and others found a $20 \%$ reduction in the risk of low weight births and a $32 \%$ reduction in very low weight births, adjusting for maternal race, age, smoking and medical complications. ${ }^{24}$ Similar findings were reported by Korenbrot and colleagues. ${ }^{25}$ Newschaffer et al, reported improvements in birth weights among HIV infected mothers participating in New York State's PCAP programme. ${ }^{26}$ After adjusting for maternal characteristics, PCAP mothers achieved $40 \%$ to $50 \%$ reductions in low birth weight and preterm deliveries. In a recent analysis of linked birth outcomes of indigent women residing in New York City, Joyce found that infants of mothers participating in the PCAP programme had a slightly higher mean birth weight than infants of non-participating mothers, a difference of $35 \mathrm{~g}^{20}$ Although the mean difference in birth weight between the groups was small, it should be noted that the analysis was restricted to term deliveries. Finally, in a clinical trial, McLaughlin and colleagues found a significant increase in birth weight for primiparous mothers randomised to receive comprehensive care compared with those receiving standard care, adjusting for demographic characteristic, obstetrical history and risk behaviours. ${ }^{24}$ There was no difference however in the incidence of low weight births.

There are at least three possible explanations for the findings. Firstly, it is possible that using nurse-midwives to administer the PCAP programme is a combination that can produce improvements in birth weights. MacDorman and Singh examined linked birth and death records of the US. Their results showed a 31\% reduction in the risk of low birth weight and a $33 \%$ reduction in the neonatal mortality for nurse-midwives compared with physicians, after controlling for social and medical factors. ${ }^{27}$ The reduction in the rates of low weight births may be directly related to the extent to which the programme and the nursemidwives reduced high risk maternal behaviours and stress, increased access to care and other beneficial behaviours, or encouraged mothers to modify adverse environments.

It is unclear, however, the degree to which prenatal factors alone account for the rates of low weight births among indigent mothers. In fact, intervention on prenatal factors or the use of midwives has not consistently led to a reduction in low birth weight infants. Randomised trials have failed to show a reduction in low birth weight and preterm birth after intervention on purported risk factors. ${ }^{13}$ Such were the findings of a recent clinical trial of 1300 women randomised to either midwife managed care or the standard shared care in Great Britain. ${ }^{16}$ Results showed that while satisfaction with care was substantially higher among women in the midwife group, there were no differences in any adverse birth outcomes. A limitation of this trial, as well as with the current study, is that the compliance with programmes and the resulting degree of behavioural change was not measured. Consequently, the degree to which behaviours were modified is unknown.

A second possible reason for the improved birth outcomes in the midwife cohort is self selection bias. That is, indigent women at low risk for adverse pregnancy outcomes selectively participated in the programme. The problem of selection bias in observational studies of pregnancy outcomes has been sited as one of the major obstacles to interpreting the effectiveness of prenatal interventions. ${ }^{28-30}$ Although we were unable to measure the effects of selection bias in this study, two points figure prominently in evaluating its influence. Firstly, if 
mothers' self selection into the cohort accounted for the entire benefit seen, then it follows that there are strong maternal, environmental, or behavioural factors that may be identified to explain the results. However, assuming that preterm birth is the intervening cause of the majority of low birth weight infants, ${ }^{23}$ known risk factors account for less than $25 \%$ of preterm births. ${ }^{911}$ Thus, selection bias on at least strong risk factors is unlikely to completely explain the results. Indeed, two of the most important of known factors-age and race-have been taken into account in this study. Secondly, cohort mothers on average started prenatal care later compared with the total county experience. To the extent that later initiation of prenatal care is a marker for other high risk behaviours, these data suggest that selection bias associated with participation should underestimate, rather than exaggerate, risk estimates.

A more probable scenario is that the reduction in risk resulted from the joint effects of a self selection process and the coordinated PCAP programme provided by the nurse midwives. It is possible that the self selection process was one in which mothers who were susceptible to behavioural interventions and education offered by the midwives were more likely to enrol in the programme than others. Although many studies and clinical trials suggest that prenatal interventions are of limited value in reducing the risk of low birth weight, some suggest that there are subgroups within indigent mothers who may benefit substantially from these. ${ }^{32}$ As an example in one trial, Olds and colleagues found that teenage mothers and smokers had significantly better pregnancy outcomes from an in-home nurse visitation programme, although for the overall study sample, the intervention was not. ${ }^{15}$ Similarly, Heins and others reported that a nurse-midwife programme failed to reduce the rate of low birth weight compared with standard care. ${ }^{13}$ Subgroup analyses suggested, however, that high risk black women in the midwife group experienced a significant reduction in the proportion of very low birth weight births compared with the control group.

Consistent with the above discussion, the one factor that may help explain the substantial benefit seen in this observational study, as well as others, compared with the generally marginal results of clinical trials is the issue of motivation and compliance with prenatal interventions. Previous studies suggest that women who have negative attitudes toward their pregnancy have a greater likelihood of delaying prenatal care and are less compliant with prenatal routines. ${ }^{33}{ }^{34}$ Moreover, attitudes and motivation can profoundly effect the results from clinical trials. As in any clinical trial, "intent to treat" analysis must aggregate the treatment effects of compliers with noncompliers. Thus the failure of clinical trials to find treatment effects may have occurred because the null effects of non-compliant mothers may have diluted the positive outcomes among compliant mothers. Indeed, in a study of smoking cessation during pregnancy,
Haddow et al found a substantial reduction in low birth weight births among women who were most compliant with the programme. ${ }^{12}$ In other words, the combination of mothers who are receptive to behavioural change coupled with an energetic and comprehensive prenatal intervention may generate the substantial benefits seen in observational studies.

Several limitations of the study need to be noted. Firstly, the study relies on two disparate sources of data, neither of which were collected for research purposes. Data for the cohort were derived from clinical and admission records, while data for the county was obtained in the form of summary tables and simple cross tabulations provided by the state. Differences in the availability and format of variables between the two data sources precluded several comparisons and statistical adjustments. Moreover, limited resources prevented our obtaining more detailed data at the individual level for either the cohort or the county. For example, data on ethnicity were not collected in any reliable fashion in the cohort. Without individual follow up, we were unable to examine the distribution of outcomes among subgroups of Hispanic women. This limitation may affect our estimates somewhat, given that there is variability among Hispanic subgroups on initiation of prenatal care and in some birth outcomes. ${ }^{35} 36$ As such, the methodology used was considered the best approach in the absence of any formal sampling or data collection procedures.

Secondly, protocols in health departments for collecting, analysing, reporting information may change over time. For example, in 1993 a new procedure for reporting the onset of prenatal care was adopted - a change primarily affecting the classification of mothers who received no prenatal. In 1994 the protocol was changed back to the original procedures. These alterations produced noticeable effects on reported proportions. In 1992 and 1994, the proportion of mothers receiving no prenatal care was $1.7 \%$ and $2.0 \%$, respectively. In 1993 , however, only one woman was reported to have received no prenatal care $(0.009 \%)$. Limitations such as these precluded analyses on some factors. On other factors, such as the proportion of mothers not receiving prenatal care, we estimated the information based on the years for which information was available.

In summary, a cohort of indigent mother receiving prenatal care and labour and delivery services through a nurse-midwife programme experienced a substantial reduction in the risk of low weight births, after adjusting for race and age. While selection biases probably explain some of the benefit, we speculate that a comprehensive nurse-midwife programme may reduce adverse pregnancy outcomes among indigent mothers who are receptive to behaviour change. Notwithstanding the inherent data problems, this study has two important implications. Firstly, mothers need not be considered at high risk for adverse pregnancy outcomes based on their socioeconomic status alone. Secondly, a comprehensive, targeted prenatal programme such as PCAP adminis- 
tered by nurse-midwifes may be a cost effective approach for reducing adverse pregnancy outcomes among indigent mothers. While each of these issues should be investigated more rigorously within the framework of compliance and attitudes toward pregnancy, nurse-midwife programmes should be expanded to provide better access to care for indigent mothers.

The authors wish to thank Dr Ray Fink for his comments and Darnee Ekmahachai, RN and Kathy Herron, CNM for their help with the data collection.

Funding: this investigation was supported with funds from the New York Medical College Research Endowment in support of the New York Medical College Intramural Research Support Program.

Conflicts of interest: none.

1 Berkowitz GS. An epidemiologic study of preterm delivery. Am f Epidemiol 1981;113:81-92.

2 Lieberman E, Ryan KJ, Monson RR, et al. Risk factors accounting for racial differences in the rate of premature birth. N Engl f Med 1987;317:743-8.

3 Parker JD, Schoendorf KC. Influence of paternal characteristics on the risk of low birth weight. Am f Epidemiol 1992; 136:399-407.

4 Starfield B, Shapiro S, Weiss J, et al. Race, family income, and low birth weight. Am ₹ Epidemiol 1991;134:1167-74.

5 Gould JB, LeRoy S. Socioeconomic status and low birth Gould JB, LeRoy S. Socioeconomic status and low birth

6 O'Campo P, Xue X, Wang M, et al. Neighborhood risk facO'Campo P, Xue X, Wang M, et al. Neighborhood risk fac-
tors for low birth weight in Baltimore: A multilevel analysis. tors for low birth weight in Baltimore:

Am f Public Health 1997;87:1113-18.
7 Kleinman JC, Madans JH. The effects of maternal smoking, physical stature, and educational attainment on the incidence of low birth weight. Am f Epidemiol 1985;121 843-55.

8 Kleinman JC, Kessel SS. Racial differences in low birth weight. N Engl f Med 1987;317:749-53.

9 Kramer MS. Determinants of low birth weight: methodological assessment and meta-analysis. Bull World Health Organ 1987;65:663-737.

10 Showstack JA. Factors associated with birth weight: An exploration of the roles of prenatal care and length of gestation. Am F Public Health 1984;74:1003-8.

11 Sexton $M$, Hebel JR. A clinical trial of change in maternal smoking and its effect on birth weight. $\mathcal{F A M A} 1984 ; 251$ : smoking

12 Haddow JE, Knight GJ, Kloza EM. Cotinine-assisted intervention in pregnancy to reduce smoking and low birth weight delivery. Br f Obstet Gynaecol 1991;98:859-65.

13 Heins HC, Nance NW, McCarthy BJ, et al. A randomized trial of nurse-midwifery prenatal care to reduce low birth weight. Obstetr Gynecol 1990;75:341-5.

14 Collaborative Group on Preterm Birth Prevention. Multicenter randomized, controlled trial of a preterm birth prevention program. Am $\mathcal{F}$ Obstet Gynecol 1993;169:352-6.

15 Olds DL, Henderson CR, Tatelbaum R, et al. Improving the delivery of prenatal care and outcomes of pregnancy: A randomized trial of nurse home visitation. Pediatrics 1986; $77: 16-28$

16 Turnbull D, Holmes A, Shields N, et al. Randomised, controlled trial of efficacy of midwife-managed care. Lancet 1996;348:213-18.

17 McLaughlin FJ, Altemeier WA, Christensen MJ, et al. Randomized trial of comprehensive prenatal care for lowncome women: Effect on infant birth weight. Pediatrics 1992;89:128-32.

18 Spencer B, Thomas H, Morris J. A randomized controlled trial of the provision of a social support service during pregnancy: the South Manchester Family Worker Project. Br f Obstet Gynaecol 1989;96:281-8.

19 Insinna T, Scelia D, Travis S. Maternal and infant data base, 1990. Tuxedo, NY: Hudson Valley Health Systems Agency, 1993.

20 Joyce $\mathrm{T}$. Impact of augmented prenatal care on birth outcomes of Medicaid recipients in New York City. Fournal of Political Economy 1999;18:31-67.

21 Fleiss JL. StatisticalmMethods for rates and proportions. New York: John Wiley, 1981.

22 National Center for Health Statistics. Advance report of final natality statistics, 1991. Hyattsville, MD: Public Health Service, 1993.

23 Paneth NS. The problem of low birth weight. In: Behrman $\mathrm{RE}$, ed. The future of children: low birth weight. Los Altos, CA: Center for the Future of Children, 1995:19-34.

24 Buescher PA, Roth MS, Williams D, et al. An evaluation of the impact of maternity care corrdination on Medicaid birth outcomes in North Carolina. Am f Public Health 1991;81:1625-9.

25 Korenbrot CC, Gill A, Clayson Z, et al. Evaluation of California's statewide implementation of enhanced perinatal services as Medicaid benefits. Public Health Rep 1995;110: 125-33.

26 Newschaffer CJ, Cocroft J, Hauck WW, et al. Improved birth outcomes associated with enhanced Medicaid prenatal care in drug-using women infected with the human immunodeficiency virus. Obstet Gynecol 1998;91:885-91.

27 MacDorman MF, Singh GK Midwifery care, social and medical risk factors, and birth outcomes in the USA. $\mathcal{F} E p i-$ demiol Community Health 1998;52:310-17.

28 Liberatos P, Kiely JL. Selected issues in the evaluation of Liberatos P, Kiely JL. Selected issues in the evaluation of
prenatal care. In: Kiely M, ed. Reproductive and perinatal epidemiology. Boca Raton: CRC Press, 1991:79-97.

29 Liu GG. Birth outcomes and the effectiveness of prenatal care. Health Serv Res 1998;32:805-23.

30 Grossman $M$, Joyce T. Unobservables, pregnancy resolution, and birth weight production functions in New York City. Fournal of Political Economy 1990;98:983-1007.

31 Tucker JM, Goldenberg RL, Davis RO, et al. Etiologies of preterm birth in an indigent population: Is prevention a logical expectation? Obstet Gynecol 1991;77:343-7.

32 Greenberg RS. The impact of prenatal care in different social groups. Am $\mathcal{F}$ Obstet Gynecol 1983; 145:797-801.

33 Joseph CLM. Identification of factors associated with delayed antenatal care. F Nat Med Assoc 1989;81:57-63.

34 Cooney JP. What determines the start of prenatal care? Med Care 1985;23:986-7.

35 Ventura SJ, Martin JA, Mathews TJ, et al. Advance report of final natality statistics, 1994. Monthly vital statistics report. Hyattsville, MD: Public Health Service, 1996

36 Singh GK, Kochanek KD, MacDorman MF. Advance report of final mortality statistics, 1994 . Monthly vital statistics report. Hyattsville, MD: Public Health Service 1996. 